\title{
"Por que você alterou isso aqui?" As razões que as crianças adotam quando fazem alterações ao revisar seus textos
}

\author{
"Why did you change this?" The reasons children adopt when revising their texts
}

\author{
Alina Galvão Spinillo \\ Universidade Federal de Pernambuco - Recife - Pernambuco - Brasil
}

$\diamond$

\begin{abstract}
Resumo: A revisão de textos é um componente da escrita que atua como um controle de qualidade do que é produzido, buscando a atender as expectativas do escritor. O presente estudo examinou as razões que crianças com diferentes níveis de domínio da escrita adotam ao revisar seus textos. Oitenta crianças do $3^{-}$e do $5^{\circ}$ ano do ensino fundamental foram solicitadas, em uma entrevista clínica, a justificar as alterações que haviam feito sobre a reprodução escrita de uma história. Verificou-se que as crianças são capazes de explicitar as razões que adotam ao revisar seus textos e que a natureza das razões variava em função do domínio que apresentam sobre a escrita, pois os alunos do 3 o ano adotavam razões relacionadas à necessidade de escrever corretamente (legibilidade, obediência às regras linguísticas), enquanto os do $5^{\mathrm{o}}$ ano adotavam tanto essas razões como outras, de natureza semântica, relativas aos propósitos comunicativos do texto.
\end{abstract}

Palavras-chave: Escrita de textos; Revisão textual; Propósitos da revisão; Crianças

\begin{abstract}
Textual revision is a component of the writing process that controls the quality of the text, seeking to meet the writer's expectations. This study examined the reasons that children with different levels of mastery of writing adopted when revising their texts. Eighty $3^{\text {rd }}$ and $5^{\text {th }}$ graders of elementary school children were asked, in a clinical interview, to justify the changes they have made in a story they had reproduced. It was found that children are able to explain the reasons they have adopted when revising their texts and that the nature of these reasons varied according to the level of mastery of writing presented by the students, as the $3^{\text {rd }}$ graders adopted reasons related to the need to write correctly (readability, obedience to linguistic rules), while the $5^{\text {th }}$ graders adopted both these and other reasons related to semantics in order to attend the communicative purpose of the text.
\end{abstract}

Keywords: Writing texts; Textual revision; Purposes of the review; Children

É inegável a natureza dinâmica da escrita de textos. Um exemplo disso é o caráter provisório que o texto assume durante o processo de composição, podendo ser retomado e alterado de forma pontual ou mesmo ser reescrito de maneira mais ampla, até que o escritor fique satisfeito com o produto gerado. Esta perspectiva é aceita por um número expressivo de estudiosos de diferentes perspectivas teóricas (e.g., ALLAL, 2000; ALLAL e CHANQUOY, 2004; CALKINS, 1989; CAMPS, 2006; FIAD, 1997; PONTECORVO e MORANI, 1996; ROCHA, 1999) e está presente em diferentes modelos de escrita propostos na literatura (ver BECKER, 2006).

Apesar da existência de diferentes modelos teóricos, esses tendem a concordar quanto ao fato de que a escrita envolve três instâncias: o planejamento, a textualização e a revisão (ALLAL e CHANQUOY, 2004; CALKINS,
1989; HAYES e FLOWER, 1980; JOLIBERT, 1994; JOLIBERT e SRAÏKI, 2008; WITTE, 1985). O presente artigo versa, especificamente, sobre a revisão textual. Segundo Fitzgerald (1987, p. 484) ${ }^{1}$

Revisão significa fazer qualquer alteração a qualquer momento do processo de escrita. Envolve identificar discrepâncias entre o texto pretendido e o texto efetivamente produzido, decidindo o que poderia ou deveria ser alterado no texto e como fazer as alterações desejadas. As alterações podem ou não afetar o significado do texto e podem ser substanciais ou mínimas As alterações podem também serem feitas na mente do escritor, antes de realizadas sobre o texto escrito, podem ser realizadas sobre o texto quando ele esta sendo escrito e/ou após o texto ter sido escrito.

\footnotetext{
Tradução nossa.
} 
A partir desta definição, verifica-se que a revisão do texto pode ocorrer em diferentes momentos da escrita. Segundo Hayes e Flower (1980) e Witte (1985), a revisão pode ocorrer:

i) no planejamento da escrita quando o escritor altera suas intenções e formulações mentais antes mesmo da escrita propriamente dita ocorrer. Neste caso, nem sempre as alterações propostas são realmente materializadas no texto, como verificado por Camps (1992).

ii) na textualização, quando o texto está ainda emergindo e as alterações são integradas ao processo de escrita enquanto o escritor revisa passagens que acabaram de ser produzidas. Bergh e Rijlaarsdam (1999) observaram que a atividade de reler partes já escritas de um texto em elaboração tinha efeito positivo sobre a geração de ideias articuladas com o que havia sido escrito anteriormente e com o que viria a seguir, refletindo sobre a qualidade do texto final produzido.

iii) na edição, quando alterações são feitas sobre uma versão relativamente completa do texto, de modo que o escritor assume o papel de leitor de seu próprio texto. Neste momento, a revisão envolve o ato de correção de erros e outras alterações que visam à melhoria da qualidade do texto sem, contudo implica alterações relativas a seu sentido global, ou seja, sem alterar as principais ideias nele veiculadas ${ }^{2}$.

Algumas poucas investigações examinam a revisão feita em diferentes momentos da escrita, sendo um raro exemplo o estudo de Chanquoy (1997) que investigava qual seria o melhor momento para se revisar. Crianças entre 8-10 anos foram solicitadas a escrever e revisar seus textos em três situações distintas: sem qualquer informação de quando revisar; fazer a revisão durante a textualização e revisar o texto no momento da edição. Os dados mostraram que o momento da revisão não era fator que influenciasse a qualidade do texto, contrariando a hipótese da autora de que a revisão após a escrita, ou seja, no momento da edição, teria um efeito mais positivo sobre a qualidade do texto do que a revisão feita durante a escrita, ou seja, no momento da textualização.

Pelo exposto, como afirmam Flower, Hayes, Schriver, Stratman e Carey (1986), a revisão é um componente na composição de textos, uma atividade recursiva presente ao longo do processo de escrita, tendo um caráter dinâmico. Revisar textos surge, portanto, como um processo de

\footnotetext{
2 Quando a revisão implica alterações amplas e substanciais, sobretudo no conteúdo e significado do texto e/ou em sua organização, observa-se um redirecionamento do texto que a literatura denomina de reescrita (FIAD, 1997; ROCHA, 1999). A edição e a reescrita são consideradas como estratégias de revisão (ALLAL e CHANQUOY, 2004; CHANQUOY, 1997; 2001; GALBRAITH e TORRANCE, 2004; GARCÍA e ARIASGUNDÍN, 2004).
}

reformulação, um controle de qualidade com vistas a melhorá-lo, solucionando os problemas identificados e atendendo às expectativas do produtor.

$\mathrm{Na}$ pesquisa relatada a seguir, a ênfase recai sobre a edição, momento em que o escritor se coloca no papel de leitor de seu próprio texto e realiza uma avaliação do que foi até então escrito, detectando a necessidade de fazer alterações sobre o que foi produzido.

Outro aspecto importante acerca da revisão diz respeito às ações realizadas pelo escritor. Fabre (1986) e Menegassi (2001) afirmam que o revisor realiza uma série de ações sobre o escrito: inserção ou acréscimo de algum elemento textual, retirada ou supressão, substituição ou troca de um elemento textual por outro; e deslocamento, que é mudar localização de elementos no texto. A substituição é a ação mais utilizada por crianças, enquanto o deslocamento é muito raro.

A natureza da alteração feita também surge como de grande relevância acerca deste tema: se a alteração incide sobre a forma ou sobre o conteúdo do texto. Dentre os aspectos relacionados à forma encontram-se as alterações de natureza gráfica, ortográfica, sintática, estrutural etc.; dentre os aspectos relacionados ao conteúdo estão incluídas as alterações de natureza semântica que buscam garantir a coerência e a precisão das informações veiculadas no texto. Existe uma forte relação entre esses aspectos, uma vez que muito do significado de um texto depende da forma como as informações são nele apresentadas.

Gelderen e Oostdam (2004), a partir de uma vasta revisão comentada da literatura, discutem acerca do papel desempenhado pela forma e pelo conteúdo no processo de revisão em escritores iniciantes, ressaltando que as crianças tendem a fazer alterações voltadas para a forma muito mais do que para os aspectos semânticos do texto, sendo isso observado tanto ao revisarem o próprio texto como ao revisarem textos escritos por outra pessoa. Os autores descrevem de modo sistemático e detalhado o impacto que alterações de forma e de conteúdo têm sobre diferentes níveis do texto (local e global), concluindo que as principais funções do revisor são checar o significado conceitual do texto e as conexões entre forma e significado. Dessas funções se derivam quatro níveis de atividades de revisão que se articulam a partir das relações entre o texto pretendido e o texto efetivamente produzido. Segundo os autores, as questões que o indivíduo procura responder ao revisar são: (i) se o significado pretendido está satisfatoriamente expresso através das formas linguísticas utilizadas; (ii) se a forma linguística do texto pretendido está adequada ao texto escrito, quando o individuo faz, então, correções (ortográficas, sintáticas etc.); (iii) se o significado do texto pretendido atende aos critérios relativos à coerência local do texto, evitando inconsistências entre segmentos; e (iv) se o significado do texto se ajusta à 
representação global do texto (sua estrutura, por exemplo) e se está coerente com conhecimentos extralinguísticos. A descrição desses níveis gerou a possibilidade de que fossem examinadas situações de instrução que viessem a facilitar o processo de revisão por parte de escritores iniciantes. A principal conclusão foi que essas situações deveriam envolver aprendizagens implícitas e explícitas sobre as formas linguísticas e a respeito do significado veiculado pelo texto.

Como mostra a literatura, muitas pesquisas examinam as ações realizadas nos diferentes momentos da escrita. Contudo, pelo conhecimento que se tem da área, não há estudos que investiguem as razões que o escritor apresenta para justificar as alterações que realiza sobre seu texto, sendo este o tema da presente investigação que tem por objetivo examinar as razões que servem de base e que determinam as alterações que as crianças fazem ao revisar seus textos após o escreverem, ou seja, no momento da edição da escrita.

Parte-se do pressuposto de que as alterações realizadas têm por finalidade geral melhorar a produção escrita, levando em consideração o texto efetivamente produzido até então (seja parte dele ou uma primeira versão de todo o texto) e o texto pretendido. No entanto, de maneira específica, torna-se importante saber se as crianças são capazes de justificar as alterações que fazem, bem como conhecer, ainda, a natureza dessas razões.

Enquanto as ações de revisão realizadas sobre um dado texto podem ser identificadas a partir da observação das alterações feitas, as razões que mobilizaram tais alterações não podem ser identificadas a partir da observação. Por exemplo ${ }^{3}$, a Figura 1 deixa claro que a alteração feita foi o acréscimo de uma marca de acentuação que estava ausente.

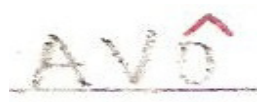

Figura 1. Exemplo de uma ação de acréscimo (inserção do acento circunflexo) realizada sobre uma palavra do texto.

Ao olhar a Figura 2 pode-se, sem qualquer dificuldade, dizer que a alteração feita foi uma retirada, em que a criança excluiu letras de uma palavra do texto.

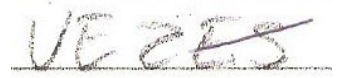

Figura 2. Exemplo de uma ação de retirada realizada sobre uma palavra do texto.

\footnotetext{
3 Os exemplos apresentados na Figura 1, na Figura 2 e na Figura 3 constam na dissertação de Lima (2011).
}

Da mesma forma, ao olhar a Figura 3, pode-se dizer que a alteração feita foi a substituição de um segmento por uma palavra.

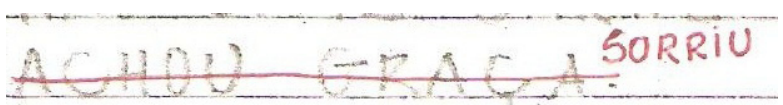

Figura 3. Exemplo de uma ação de substituição realizada sobre um segmento do texto (substituição de um segmento por uma única palavra).

No entanto, apesar da facilidade em identificar a ação realizada e a unidade linguística alterada, não é possível saber quais as razões que a criança tinha em mente ao realizar tais alterações.

De acordo com nossa análise, há duas maneiras de se conhecerem as razões que levam o escritor a fazer alterações em seu texto: (i) as razões podem ser inferidas, ou (ii) podem ser explicitadas pelo próprio escritor. $\mathrm{Na}$ pesquisa descrita a seguir, optou-se por esta segunda alternativa.

Em uma perspectiva de desenvolvimento, o presente estudo procurou examinar se haveria um efeito da idade/ escolaridade sobre as razões que as crianças adotam ao revisar seus textos. Será que crianças mais velhas e em anos escolares mais adiantados e que, portanto, já dominam a escrita de maneira mais autônoma forneceriam razões diferentes daquelas apresentadas por crianças mais jovens e em anos escolares iniciais que apresentam pouco domínio da escrita?

\section{Método}

\section{Participantes}

Oitenta crianças de classe média alunas de escolas particulares na cidade de Recife foram igualmente divididas em dois grupos: Grupo 1, formado por alunos do $3^{\circ}$ ano do ensino fundamental com 8 anos de idade (média: 8a7m); e Grupo 2, formado por alunos do 5o ano do ensino fundamental com 10 anos de idade (média: $10 \mathrm{a} 4 \mathrm{~m})$.

\section{Material e procedimento}

O estudo foi realizado em duas sessões, com um intervalo de sete a dez dias entre elas. Na primeira sessão, de forma coletiva na sala de aula, solicitava-se que cada participante reproduzisse por escrito uma história lida em voz alta pela examinadora (Anexo I). Cada um recebia uma cópia impressa dessa história para acompanhar, individualmente, a leitura. Em seguida, a cópia era recolhida, sendo entregue uma folha de papel pautado em branco, lápis e borracha. 
A opção pela reprodução de um texto, ao invés da produção livre como ocorre na grande maioria dos estudos na área, deveu-se ao fato de que a revisão textual requer lidar com dois textos simultaneamente: o texto efetivamente produzido (aquele que está sendo escrito) e o texto pretendido (aquele que se tem em mente escrever) os quais precisam ser comparados pelo escritor. Ao fazer tal comparação, torna-se possível detectar diferenças entre o texto pretendido e aquele que foi produzido (ou que está sendo produzido) e então realizar as alterações necessárias para tornar o texto escrito a expressão do texto pretendido. Ao ser solicitado a reproduzir um texto, o texto que serve de base para a reprodução corresponde ao texto pretendido. Do ponto de vista metodológico, a reprodução torna possível a materialização do texto pretendido, assim como o torna o mesmo para todos os escritores.

$\mathrm{Na}$ segunda sessão, a examinadora entregava individualmente a cada participante lápis, borracha e uma cópia impressa do texto que havia sido por ele reproduzido na primeira sessão, dizendo que aquele texto poderia ser melhorado, podendo proceder às alterações que achasse necessárias. A examinadora lia a historia original que servira de base para a reprodução escrita.

Concluída a revisão, a criança era perguntada a respeito de cada alteração que havia realizado e das razões que haviam norteado tais alterações. Isso era feito a partir de uma entrevista de natureza clínica que tinha por base duas perguntas-chave: "Que alteração você fez aqui?", "Por que você fez esta alteração?" A entrevista foi gravada em áudio e transcrita para análise.

\section{Resultados}

A partir das alterações realizadas por todas as crianças investigadas foi possível classificar as razões em sete diferentes tipos, como descrito e exemplificado a seguir.

TIPO 1 (sem explicação): a criança afirma não saber explicar a razão de ter feito aquela alteração ou fornece uma resposta que não deixa clara a razão adotada.

Exemplo 1 (ação de substituição):

C: Eu tirei um olho grandão e botei olhos enormes. Porque assim fica melhor.

E: Melhor como?

C: Assim fica melhor. Eu acho.

Exemplo 2 (ação de retirada):

C: Eu tirei essa parte daqui (não podia pegar) porque não estava bom.

E: Por que não estava bom?

$\mathrm{C}$ : Porque estava ruim.
TIPO 2 (evitar repetição): a alteração é feita com o propósito de evitar o uso frequente de uma mesma palavra, expressão ou de um segmento de frase. Apenas ações de retirada e de substituição foram realizadas.

Exemplo 3 (ação de substituição):

E: Por que você trocou a palavra gato pela palavra ele?

C: Porque esta palavra é diferente. É outra palavra, para não botar ele de novo, não é? Fica melhor assim, sem repetir, repetir, repetir. A professora diz que é feio repetir, repetir.

Exemplo 4 (ação de retirada):

C: (riscou a palavra ele).

E: Por que riscou esta palavra?

C: Ele, ele, ele (apontando cada palavra repetida). Porque era a mesma palavra, a mesma palavra de novo, dizendo a mesma coisa. É por isso que tinha que sair.

TIPO 3 (garantir a legibilidade): alterações de natureza gráfica em que a ação incide sobre a caligrafia de uma palavra para torná-la legível. Esta alteração pode ser a reescrita de toda a palavra ou refazer o contorno de suas letras.

Exemplo 5 (ação de substituição):

C: (riscou a palavra dono e a reescreve).

E: Por que fez isso nesta palavra?

C: Estava parecendo outra palavra que não era dono. Aí risquei tudo e escrevi de novo, com letra bonita. É que eu estava com pressa quando escrevi isso.

Exemplo 6 (ação de substituição):

C: (reforçou o ponto na letra $i$ das palavras gatinho e muito).

E: Por que fez isso aqui nesta letrinha?

C: Aqui é uma bolinha. Antes, isso aqui estava parecendo mais um agudo. Agora está bom.

Exemplo 7 (ação de substituição):

C: (contornou a letra $u$ da palavra $d e u$ ).

E: Por que você fez assim nesta palavra?

$\mathrm{C}$ : Aqui parece um dem, ai tem que afundar mais pra ficar deu.

TIPO 4 (escrever corretamente): a criança faz acréscimo, retirada ou substituição com o propósito de obedecer as regras da língua materna.

Exemplo 11 (ação de acréscimo):

C: (acrescenta $s$ na palavra olho)

E: E aqui, por que você fez assim?

C: Eu botei $s$ no final porque era plural, ai tem que ter o $s$ quando é plural. 
Exemplo 12 (ação de retirada):

C: (riscou a letra $i$ da palavra oilhar).

E: Por que você acha que tem que tirar o $i$ ?

C: Porque está errado. É olhar e não oilhar.

Exemplo 13 (ação de acréscimo):

$\mathrm{C}$ : (adicionou um ponto final em uma frase).

E: Por que colocou esse ponto ai?

C: Porque é o final da frase, não é? Fica errado se não coloca o ponto final. É o ponto final e ai tem que usar a letra maiúscula depois do ponto. É sempre assim. Tem que escrever do jeito certo.

Exemplo 14 (ação de acréscimo):

C: $\quad$ (acrescentou a letra $n$ na palavra oça)

E: Você botou a letra $n$ por quê?

C: Não podia ficar oça, é onça. Eu escrevi errado, me distraí porque eu sei como escreve onça.

Exemplo 15 (ação de substituição)

C: (substituiu vio por viu)

E: Por que você mudou esta palavra?

C: Porque estava errado. É viu com $u$.

Exemplo 16 (ação de substituição):

C: (substituiu dinovo por de novo).

E: E aqui. Por que mudou assim?

C: Era duas palavras separadas. Às vezes eu faço uns errinhos feito esse. Mas ai eu corrijo logo e a tia nem vê (risos).

TIPO 5 (garantir a compreensão): a criança acrescenta uma palavra ou um segmento de frase com vistas a garantir a compreensão, seja esclarecendo algum ponto ou completando o texto com informação que acredita estar ausente. Apenas a ação de acréscimo foi observada.

Exemplo 17 (ação de acréscimo):

C: (acrescentou a palavra para em uma frase)

E: Por que achou que tinha que botar esta palavra aqui?

C: Escrevi um para depois de espelho porque estava faltando essa palavra. Não dava para entender direito o que era.

Exemplo 18 (ação de acréscimo):

C: (acrescentou o gato viveu feliz para sempre ao final da última frase do texto).

E: Por que achou melhor colocar isso aqui?

C: É porque tinha mais coisas para dizer. Eu tinha se esquecido de escrever o gato viveu feliz para sempre.

TIPO 6 (ser fiel ao texto original): a criança faz retirada, substituição e acréscimo com o propósito de manter-se fiel ao conteúdo veiculado no texto que servira de base para a reprodução.
Exemplo 19 (ação de retirada):

C: (retirou um segmento de frase: a mãe do dono reclamava do gato).

E: Por que tirou esta parte?

C: Eu tirei esse pedaço porque não tinha desse jeito na história. Lá não dizia que a dona tinha reclamado do gato.

Exemplo 20 (ação de substituição):

C: (substituiu a palavra cavalo por onça).

E: Por que trocou a palavra?

C: Porque na história era a onça.

Exemplo 21 (ação de substituição):

C: (substituiu a palavra quarto por banheiro)

E: Por que você colocou banheiro no lugar de quarto?

C: Na história não era quarto, era banheiro. $\mathrm{O}$ espelho foi para o banheiro.

Exemplo 22 (ação de acréscimo):

C: (acrescentou o segmento Ele gostava muito das brincadeiras de seu dono).

E: Então? Colocou mais esta parte? Por quê?

$\mathrm{C}$ : Porque tinha isso na história que a senhora leu.

Exemplo 23 (ação de substituição):

C: (substituiu a palavra pescoço pela palavra cabeça).

E: Por que trocou de palavra?

C: Troquei porque na história foi a cabeça e não o pescoço que virava de lado. $\mathrm{O}$ gato ficava mexendo a cabeça. $\mathrm{O}$ pescoço eu acho que não mexia não. Só diz a cabeça.

TIPO 7 (ser coerente com o conhecimento de mundo): a criança faz alterações com o propósito de ser coerente com o conhecimento de mundo que possui. Apenas ações de substituição foram encontradas.

Exemplo 24 (ação de substituição):

C: (substituiu a palavra gaiola por caminha).

E: Por que trocou de palavra?

C: Já viu gato em gaiola? Ele fica na caminha dele, ou no sofá, em cima da cama. Minha mãe reclama quando ele sobe na cama.

Exemplo 25 (ação de substituição):

C: (substituiu gritar bem forte por miou alto).

E: Por que fez isso aqui?

C: Eu tirei gritar bem forte e botei miou alto porque gato não grita, ele mia.

As razões apresentadas foram analisadas por dois juízes independentes, havendo $95,4 \%$ de concordância entre eles. Os casos de discordância foram julgados por um terceiro juiz, também independente, cuja classificação foi considerada final. 
Como mostra a Tabela 1, os grupos não apresentam o mesmo padrão de resultados.

Tabela 1. Porcentagem dos tipos de razões apresentadas em cada grupo de participantes.

\begin{tabular}{ccc}
\hline Razões & $\begin{array}{c}\text { Grupo 1 (3} \text { ano) } \\
(\mathbf{n}=\mathbf{6 0 4})\end{array}$ & $\begin{array}{c}\text { Grupo 2 (5 ano) } \\
(\mathbf{n}=\mathbf{5 3 7})\end{array}$ \\
\hline Tipo 1 & 1,5 & 0,9 \\
Tipo 2 & 4,9 & 2,4 \\
Tipo 3 & 1,6 & 1,1 \\
Tipo 4 & 69,4 & 38,9 \\
Tipo 5 & 8,6 & 18,3 \\
Tipo 6 & 12,7 & 37,2 \\
Tipo 7 & 1,2 & 1,2 \\
\hline
\end{tabular}

Tipo 1: sem explicação; Tipo 2: evitar repetição; Tipo 3: garantir a legibilidade Tipo 4: escrever corretamente; Tipo 5: garantir a compreensão; Tipo 6: ser fiel ao texto original; Tipo 7: ser coerente com o conhecimento de mundo.

O Teste de Friedman identificou diferenças significativas entre os tipos de razões tanto no Grupo 1 $(\mathrm{p}=0,001)$ como no Grupo $2(\mathrm{p}=0,001)$. De acordo com o Teste de Wilcoxon, isso ocorreu porque no Grupo 1 as razões se concentravam no Tipo 4 (escrever corretamente: $69,4 \%$ ), sendo elas significativamente mais frequentes que as demais razões $(\mathrm{p}<0,001)$. No Grupo 2 , o teste mostrou que razões do Tipo 4 (escrever corretamente: $38,9)$ e do Tipo 6 (ser fiel ao texto original: $37,2 \%$ ) eram mais frequentes do que os demais tipos $(p<0,001)$.

O Teste U de Mann-Whitney revelou que os grupos variavam apenas em relação às razões Tipo $4(p<0,001)$; Tipo $5(\mathrm{p}<0,01)$; e Tipo $6(\mathrm{p}<0,001)$. Como pode ser visto na Tabela 1, as razões Tipo 4 (escrever corretamente) eram mais utilizadas pelas crianças do Grupo $1(69,4 \%)$ do que pelas do Grupo 2 (38,9\%), enquanto que as razões Tipo 5 (garantir a compreensão) e Tipo 6 (ser fiel ao texto original) eram mais adotadas pelo Grupo 2 (Tipo 5: $18,3 \%$ e Tipo 6: $37,2 \%$ ) do que pelo Grupo 1 (Tipo 5: $8,6 \%$ e Tipo $6: 12,7 \%$ ).

Observa-se, portanto, que o padrão de resultados é diferente entre os grupos: enquanto as crianças mais novas e com escolaridade mais inicial fazem alterações com o propósito de escrever corretamente, procurando obedecer às regras ortográficas e gramaticais do português, as crianças mais velhas e em nível escolar mais adiantado além deste tipo de preocupação também se voltam para a necessidade de fazer alterações de natureza semântica que garantam que a reprodução feita seja compreendida pelo leitor e seja fiel ao conteúdo veiculado no texto original.

Como forma e conteúdo são aspectos importantes na escrita de textos, como anteriormente mencionado, as razões apresentadas pelos participantes de ambos os grupos foram agrupadas em duas grandes classes (Tabela 2): razões relacionadas a alterações de forma (evitar repetição, garantir a legibilidade e escrever corretamente) e razões relacionadas a alterações de conteúdo (garantir a compreensão, ser fiel ao texto original e ser coerente com o conhecimento de mundo).

Tabela 2. Porcentagem de razões relativas à forma e ao conteúdo em cada grupo de participantes ${ }^{4}$.

\begin{tabular}{lcc}
\hline $\begin{array}{c}\text { Natureza } \\
\text { das razões }\end{array}$ & $\begin{array}{c}\text { Grupo 1 (3ㅇ ano) } \\
\text { (n=595) }\end{array}$ & $\begin{array}{c}\text { Grupo 2 (5o ano) } \\
\text { (n=532) }\end{array}$ \\
\hline Forma & 77,1 & 42,9 \\
Conteúdo & 22,9 & 57,1 \\
\hline
\end{tabular}

Forma: somatório das razões Tipo 2, Tipo 3 e Tipo 4; e Conteúdo: somatório das razões Tipo 5, Tipo 6 e Tipo 7.

O Teste U de Mann-Whitney identificou diferenças significativas entre os grupos tanto em relação à forma $(\mathrm{p}<0,001)$ como em relação ao conteúdo $(\mathrm{p}<0,001)$. Alterações feitas para atender aos aspectos formais do texto eram muito mais adotadas pelas crianças do Grupo 1 (77,1\%) do que pelas do Grupo 2 (42,9\%), enquanto que alterações relativas ao conteúdo eram mais frequentes entre as do Grupo 2 do que entre as do Grupo 1.

A frequência de razões de forma e de conteúdo difere significativamente entre as crianças do Grupo 1, conforme revelado pelo Teste de Friedman $(p<0,001)$. O que se verifica é que a maioria das alterações feitas pelas crianças do Grupo 1 era de forma $(77,1 \%)$, sendo menos frequentes as alterações relativas ao conteúdo $(22,9 \%)$. Este padrão de resultados não foi observado entre as crianças do Grupo 2, cujas alterações se distribuem de modo mais equilibrado entre forma $(42,9 \%)$ e conteúdo $(57,1 \%)$. Isso indica que, com o aumento do conhecimento sobre a escrita, as crianças do Grupo 2 passam a preocupar-se não apenas com questões de natureza formal tais como legibilidade e obediência às regras ortográficas e gramaticais, mas também se preocupam com questões de natureza semântica na tentativa de conferir clareza ao texto, ser fiel ao texto original no qual a reprodução se baseava.

\section{Conclusões e discussão}

Os resultados do presente estudo mostraram que as crianças são capazes de explicitar as razões que norteiam as alterações que fazem em seus textos ao revisá-los. Mas quais são as razões que adotam ao fazer tais alterações? Esta foi a principal pergunta que o presente estudo procurou responder, buscando-se, ainda, examinar se essas razões variavam em função do domínio que as crianças apresentavam sobre a escrita. Nesta investigação

\footnotetext{
4 Respostas Tipo 1 (sem explicação) não foram computadas por não ser possível determinar se as razões eram de forma ou de conteúdo.
} 
considerou-se o nível de escolaridade dos participantes, no caso $3^{\mathrm{O}}$ e $5^{\mathrm{O}}$ ano do ensino fundamental, como indicador do domínio sobre a escrita, de modo que as crianças alunas do $5^{\circ}$ ano foram consideradas como tendo um maior domínio da escrita do que as crianças alunas do $3^{\circ}$ ano.

A partir de uma entrevista clínica foi possível identificar as razões que norteavam as alterações que as crianças faziam sobre seus textos, as quais atendiam aos propósitos variados que expressavam preocupações que o escritor tinha com aspectos formais (legibilidade e regras do português) e com aspectos semânticos (conteúdo) do texto. Embora não se pretenda propor uma tipologia de razões que norteie a revisão textual, os dados obtidos parecem apresentar certo grau de generalidade acerca dos propósitos que levam o escritor a fazer alterações em seu texto. Comentário, entretanto, precisa ser feito em relação a um tipo de razão que foi identificado, que parece ser consequência da situação de escrita proposta aos participantes nesta investigação: a preocupação do escritor em ser fiel ao texto original. Caso o texto a ser escrito fosse uma história original, evidentemente, este tipo de razão não justificaria as alterações do escritor sobre seu texto. A reprodução escrita, portanto, gera esta necessidade.

Comparações entre os grupos de participantes evidenciaram que escrever corretamente é um propósito que norteia as alterações feitas tanto por escritores que apresentam um maior domínio da escrita como por escritores que não possuem este domínio. No entanto, escritores com um maior domínio da escrita além deste tipo de preocupação também fazem alterações de natureza semântica. Uma explicação para isso é que essas crianças, por dominarem as regras da língua, cometem menos erros de forma e este domínio permite que se voltem para outros aspectos da escrita mais relacionados à comunicação, como por exemplo, tornar o texto reproduzido fiel ao texto original e mais claro e preciso para um possível leitor. Assim, preocupações de natureza semântica além de preocupações de natureza formal passam, conjuntamente, a fazer parte do repertório de razões que justificam as alterações feitas pelo escritor mais competente. De fato, a revisão envolve um trabalho mental sobre vários aspectos do texto e isso parece estar subjacente às alterações feitas pelas crianças com um maior domínio da escrita, como evidenciado neste estudo.

A reprodução escrita permite materializar o texto pretendido, tornando mais evidente para o escritor as discrepâncias entre o que é pretendido e o que foi efetivamente produzido, ressaltando o caráter de resolução de problemas que a revisão assume, como afirmam Hayes e Flower (1980). A reprodução de texto ilustra as operações cognitivas descritas no modelo de
Bereiter e Scardamalia (1987) e nas instâncias descritas por Gelderen e Oostdam (2004) relativas à insatisfação do escritor com o texto até então produzido, visto que este apresenta discrepâncias, ou mesmo um distanciamento, quando comparado ao texto pretendido que neste estudo era materializado na história a ser reproduzida. Dentro deste cenário, a reprodução pode tornar-se um recurso metodológico interessante para os estudiosos da revisão textual.

Pelo que se sabe da literatura na área, não se conhecem pesquisas que investiguem as razões que escritores adotam ao revisar seus textos, fato este que confere ao presente estudo um caráter inovador e exploratório, gerando a necessidade de examinar outras facetas deste tema. Por exemplo, pesquisas futuras poderiam investigar este aspecto em adultos em processo de alfabetização que embora sejam escritores iniciantes apresentam um perfil distinto dos escritores iniciantes infantis. Na realidade, muito há a ser examinado sobre esta faceta da revisão textual.

\section{Referências}

ALLAL, L.; CHANQUOY, L. Introduction: revision revisited. In: ALLAL, L.; CHANQUOY, L.; LARGY, P. (Org.). Revision: cognitive and instructional process. Londres: Kluwer Academic Press, 2004. p. 1-8. http://dx.doi.org/10.1007/978-94-007-1048-1

ALLAL, L. Metacognitive regulation of writing in the classroom. Metalinguistic activity: the link between writing and learning to write. In: CAMPS, A.; MILIAN, M. (Org.). Metalinguistic activity in learning to write. Amsterdam: Amsterdam University Press, 2000. p. 145-166.

BECKER, A. A review of writing model research based on cognitive processes. In: HORNING, A.; BECKER, A. (Org.). Revision: history, theory, and practice. United States of America: Parlor Press, 2006. p. 25-50.

BEREITER, C.; SCARDAMALIA, M. The Psychology of written composition. Hillsdale: Erlbaum, 1987.

BERGH, H.; RIJLAARSDAM, G. The dynamics of idea generation during writing: an on-line study. In: TORRANCE, M.; GALBRAITH, D. (Org.). Knowing what to write: conceptual processes in text production. Amsterdam: Amsterdam University Press, 1999. p. 99-137.

CALKINS, L. M. A arte de ensinar a escrever: o desenvolvimento do discurso escrito. Porto Alegre: ArtMed, 1989.

CAMPS, A. Some observations about adolescents' capacity to revise written texts. Infancia y Aprendizaje, v. 58, p. 65-81, 1992. http://dx.doi.org/10.1080/02103702.1992.10822333

CAMPS, A. Texto, processo, contexto, atividade discursiva: diferentes pontos de vista sobre a atividade de aprender e de ensinar a escrever. In: CAMPS, A. (Org.). Propostas didáticas para aprender a escrever. Porto Alegre: Artmed, 2006. p. 13-32.

CHANQUOY, L. Thinking skills and composing: assessment (and treatment) strategies for text revisions. In: HAMERS, J.H.M.; OVERTOM, M. (Org.). Inventory of European programmes for teaching. Utrecht: Sardes, 1997. p. 179-185. 
FABRE, C. Des variantes de brouillon au cours préparatoire. Études de Linguistique Appliquée, v. 62, p. 59-79, 1986.

FIAD, R. S. (Re)escrevendo: o papel da escola. In: ABAURRE, M.B.M; FIAD, R. S. Mayrink-Sabinson, M.L. (Org.). Cenas de aquisição da escrita: o sujeito e o trabalho com o texto. São Paulo: Associação de Leitura do Brasil, 1997. p. 72-77.

FITZGERALD, J. Research on revision in writing. Review of Educational Research, v. 57, p. 481-506, 1987. http://dx.doi. org/10.3102/00346543057004481

FLOWER, L. S.; HAYES, J. R.; SCHRIVER, K.; STRATMAN, J.; CAREY, L. Cognitive processes in revision. In: ROSENBERG, S. (Org.). Reading, writing, and language learning: advances in applied psycholinguistics. Cambridge: Cambridge University Press, 1986. p. 176-240.

GELDEREN, A.; OOSTDAM, R. (2004). Revision of form and meaning in learning to write comprehensible text. In: ALLAL, L.; CHANQUOY, L.; LARGY, P. (Org.). Revision: cognitive and instructional process. Londres: Kluwer Academic Press, 2004. 103-124. http://dx.doi.org/10.1007/978-94-007-1048-1_7

HAYES, J. R.; FLOWER, L. Identifying the organization of writing processes. In: GREGG, L. W.; STEINBERG, E. R. (Org.). Cognitive processes in writing: an interdisciplinary approach. Hillsdale: Lawrence Erlbaum, 1980. p. 3-30.
JOLIBERT, J. Formando crianças produtoras de textos. Porto Alegre: Artmed, 1994.

JOLIBERT, J.; SRAÏKI, C. Caminhos para aprender a ler $e$ escrever. São Paulo: Contexto, 2008.

LIMA, I. D. M. de. Revisão textual: comparando-se crianças e adultos em processo de alfabetização. Dissertação (Mestrado) - Programa de Pós-Graduação em Psicologia Cognitiva da Universidade Federal de Pernambuco, Recife, 2011 .

MENEGASSI, R. J. Da revisão a reescrita: operações linguísticas sugeridas e atendidas na construção do texto. Mimesis, v. 22, n. 1, p. 49-68, 2001.

PONTECORVO, C.; MORANI, R. M. Looking for stylistic features in children composing stories: products and processes. In: PONTECORVO, C.; ORSOLINI, M.; BURGE, B.; RESNICK, L. B. (Org.). Children's early text construction. Mahwah: Lawrence Erlbaum, 1996. p. 229-258.

ROCHA, G. A apropriação das habilidades textuais pela criança. São Paulo: Papirus, 1999.

WITTE, S. P. Revising, composing theory, and research design. In: FREEDMAN, S. W. (Org.). The acquisition of written language: response and revision. Norwood: Ablex, 1985. p. 250-284.

\section{ANEXO I História ${ }^{5}$ lida pela examinadora}

Bingo era um gato de bom gênio, que todo se encantava com as festinhas do seu dono. Além disso, ficava de olhos duros, como que apaixonado, ouvindo as cantigas dos passarinhos nas gaiolas. Aconteceu que a mãe do dono do gato um dia comprou um espelho para retocar a pintura da face. Era um espelho especial, que aumentava muitas vezes. Bingo, que era muito curioso, vinha espiar todos os embrulhos, tudo que chegava de novo na família. Foi-se chegando, foi-se chegando, e olhou a novidade no banheiro. Então, levou um susto.

- Meu Deus, que onça horrível!

Mas, como a onça não saísse de dentro do espelho, ele resolveu espiar mais uma vez, bem de mansinho, para ver se era um retrato de onça que haviam pendurado ali. Primeiro, viu o olhão da onça; em seguida, a orelhona e, como entortasse a cabeça, reparou que a onça, igualzinho, também entortava. Aí, seu coração quase parou. Havia feito, pensava, a mais incrível das descobertas. Soltou um "miau" de alegria e de orgulho e, por fim, disse:

- Gente, a onça sou eu, a onça sou eu.

Recebido: 27 de agosto de 2014

Aprovado: 07 de novembro de 2014

Contato: alinaspinillo@hotmail.com

\footnotetext{
5 Texto adaptado de Queiroz, D. S. de. (s/d). Carrapinhão. Em H. Sargentim \& M. D. Fernandez. Atividades e Comunicação (leitura - gramática): Língua Portuguesa. $2^{\mathrm{a}}$ Série. São Paulo: IBEP.
} 